Egyptian Journal of Aquatic Biology \& Fisheries

Zoology Department, Faculty of Science,

Ain Shams University, Cairo, Egypt.

ISSN $1110-6131$

Vol. 23(3): 13 - 25 (2019)

www.ejabf.journals.ekb.eg

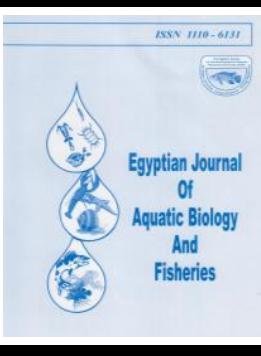

\title{
Optimum contribution of dietary protein: energy ratio in the grey mullet (Mugil cephalus, linnaeus, 1758) diets
}

\author{
Abdel-Moniem M. Yones ${ }^{1 *}$, Ahmed Kamel Ibrahim El-Hammady ${ }^{1}$, Aliaa M. El- \\ Kasheif $^{2}$ and Midhat A El-Kasheif ${ }^{1}$. \\ 1-National Institute of Oceanography and Fisheries (NIOF) Cairo, Egypt. \\ 2- Faculty of Fish Resources, Suez University, Suez. \\ *Corresponding author:yones_55200010@yahoo.com
}

\section{ARTICLE INFO \\ Article History: \\ Received: April 12, 2019 \\ Accepted:May 29, 2019 \\ Online: June 2019}

Keywords:
Mugil cephalus
Protein
Energy
Lipid
Carbohydrate
growth performance
feed efficiency

The effect of varying dietary protein and energy levels on the growth performance, feed efficiency and tissue chemical composition by increasing dietary energy sources (lipids and carbohydrates) for flathead grey mullet, Mugil cephalus fingerlings were evaluated. Twelve experimental diets were formulated by four different dietary protein levels $(25,30,35$ and 40) combined with three different gross energy levels $(16,17$ and $18 \mathrm{MJ} / \mathrm{kg}$ diet) to provide 12 different dietary protein: energy ratios $(15.43,14.40,13.64$, 18.60, 17.46, 16.42, 21.63, 20.73,19.20, 24.26, 23.02 and $21.79 \mathrm{MJ} / \mathrm{kg}$ diet). The present results showed that, the highest final body weight, weight gain, specific growth rate, feed efficiency and protein efficiency ratio values were recorded with increasing of dietary protein levels from 25 up to $35 \%$, irrespective of dietary energy levels. However, irrespective of dietary protein levels, the increasing dietary energy levels (from 16 to18 $\mathrm{MJ} / \mathrm{Kg}$ diet) obtained slightly final body weight, weight gain, specific growth rate, feed efficiency and protein efficiency ratios. Feed conversation ratio values decreased $(P \geq 0.05)$ either with increasing dietary crude protein or dietary energy levels. The best FCR value was recorded with dietary energy 18 $\mathrm{MJ} / \mathrm{kg}$ and $35 \%$ protein. No statistical differences $(P>0.05)$ were observed for the effect of dietary protein energy ratios on whole body proximate analysis except for body ether extract contents. The body lipid deposition may indicate that, when dietary lipid was supplied in excess, a proportion of this lipid was deposit as fats. Concomitant increase $(P<0.05)$ of body lipid and protein retained were observed with increase dietary lipid levels, while negative effect on energy retained was recorded with increase energy levels. These results suggested that the diet contains $30 \%$ crude protein with $18 \mathrm{MJ} / \mathrm{kg}^{-1}$ gross energy enhanced the growth performance and feed efficiency of Mugile cephalus, had protein-sparing effect and increased the utilization of each dietary protein and energy sources.

\section{INTRODUCTION}

Grey mullet, Mugil cephalus is an extremely wide spread fish species. This specie is found in temperature and tropical waters throughout the world (Kanimozhi et al.,2013). The majority of studies (Blaber,1976, Mincklcy1982,Romer and Mclachlan, 1986) on different species of mullet (Mugil cephalus and Liza ramada) have shown that the adult fish diet $(>30 \mathrm{~mm})$ consists of detritus, diatoms, sand 
grains, crustaceans, algae and decomposed organic matter. The studies on juvenile mullet (fish<30mm), which done by (De silva,1980 and Loftus et al.,1983), reported that juveniles are mainly carnivorous, eating planktons, micro-crustaceans, shrimp larvae and zooplankton. Fernandez (2014) showed that the diet of Mugil cephalus was composed of upwelling diatom (pelagic and benthic), dino flagellates (cosmopolitan and thermophilia), silica flagellates, tintinnids, copepoda, euphauslacea occasional organisms and unidentified organic remains.

Carbohydrate, protein, and lipid are used as energy sources by fish, but these organic compounds are not equally well suited for the promotion of growth and the optimal nutrient composition of feeds varies between fish species (Klaoudatos et al.,2005). While herbivorous and omnivorous fish accept more than 25\% carbohydrate in their diet, carnivorous fish have optima below 20\% (Wilson,1994). The ratio of dietary protein to energy is important for production more economical feeds and to minimize adverse environmental impacts (Kaushik and Medale,1994). Protein is the cost lest micronutrient in any feed and its share is high in fish feed. Therefore, replacing dietary protein by carbohydrate or lipid not only reduces production cost but also nitrogen effluent from the culture system (Wu et al.,2007). Commercial fish feed formulations tend to increase dietary lipid levels to improve feed utilization for the optimization of production (Caballero et al.,1999). Actually in fish feed production sector it's reasonable to increase lipid content, spare protein, improve feed conversion, decrease the amount of waste production by the fish. Additionally, special attention is being given to the development of practical feeds that maximize nutrient retention and minimize nutrient loss (Tacon,1997). Furthermore, carbohydrate, if well utilized by fish, would be more economic compared with lipid because of it's cheaper cost and better availability, although lipid constitutes an important source of non-protein energy source for fish (Kaushik et al.,1989). Though, (Cowey and Walton, 1989 and Wilson,1994) reported that, provide an adequate carbohydrate level in fish diet can reduce catabolism of protein for energy and for synthesis of glucose, which secondly reduces protein and increases nitrogen release.

From both economic and environmental point of view for aquaculture, the present study aiming to determine the effect of varying dietary protein and energy levels on the growth performance, feed efficiency and tissue chemical composition by increasing dietary energy sources (lipids and carbohydrates) for flathead grey mullet, Mugil cephalus fingerlings.

\section{MATERIALS AND METHODS}

\section{Experimental diets}

Twelve experimental diets were formulated by four different dietary protein levels $(25,30,35$ and 40$)$ combined with three different dietary gross energy $(16,17$ and $18 \mathrm{MJ} / \mathrm{kg}^{-1}$ diet) to provide 12 different dietary proteins: energy ratios as: 15.43 , 14.40, 13.64. 18.60, 17.64, 16.42, 21.63, 20.37,19.20, 24.26, 23.02 and 21.79 as presented in (Table, 1). Diets were pelleted with laboratory pellet mill without steam conditions and stored at $4^{\circ} \mathrm{C}$ until use. The feed ingredients and experimental diets were analyzed following the procedure of (AOAC, 2006). The gross energy (MJ $\mathrm{kg}^{-1}$ diet) contents of the diets and fish were calculated by using the following calorific values: $23.9,39.8$ and $17.6 \mathrm{kjg}^{-1}$ diet for protein, either extract and nitrogen free extract, respectively (NRC, 2011). 


\section{Fish experimental conditions}

Twenty four rectangular fiberglass tanks $(800 \mathrm{~L}$ each) were used and supplied with saline water, which passed through two sandy filters. Physicochemical characteristics of water tanks were: salinity $\left(33.2 \pm 1.4 \mathrm{~g} \mathrm{~L}^{-1}\right)$, water temperature $\left(26.2 \pm 2.7^{\circ} \mathrm{C}\right)$, dissolved oxygen $\left(5.2 \pm 0.8 \mathrm{mgL}^{-1}\right), \mathrm{pH}(7.8 \pm 0.1)$, and unionized ammonia $(0.03 \pm 0.01)$ during the experimental period, to maintain water quality within the optimum range for Mugil cephalus as recorded by (Abdel-Tawwab et al., 2005). Grey mullet, Mugil cephalus (Linn) fingerlings were obtained from a local commercial farm and acclimated to the laboratory conditions for two weeks. Fish was fed daily ad-libitum on a commercial diet $(30 \% \mathrm{CP})$. Fingerlings (mean initial weight $30.23 \pm 1.87 \mathrm{~g}$ ) were randomly distributed at 40 fingerlings per tank using two replicates for each treatment. The experimental period lasted 126 days after start (1June tell $4^{\text {th }}$ October, 2016). All groups of fish were fed with the experimental diet to visual satiation by hand two times a day (08.00 am and $16.00 \mathrm{pm})$. Fish were weighed every 2 weeks to adjust the amount of feed consumed.

Table 1: Ingredients content and proximate composition of experimental diets.

\begin{tabular}{|c|c|c|c|c|c|c|c|c|c|c|c|c|}
\hline \multirow{2}{*}{$\begin{array}{l}\text { Protein \% } \\
\text { Energy }(\mathrm{MJ} / \mathrm{Kg})\end{array}$} & \multicolumn{3}{|c|}{25} & \multicolumn{3}{|c|}{30} & \multicolumn{3}{|c|}{35} & \multicolumn{3}{|c|}{40} \\
\hline & 16 & 17 & 18 & 16 & 17 & 18 & 16 & 17 & 18 & 16 & 17 & 18 \\
\hline Fish meal & 12.3 & 12.3 & 12.3 & 18.0 & 18.0 & 25.5 & 25.5 & 25.7 & 26.3 & 31.2 & 31.2 & 31.2 \\
\hline Meat meal & 7.1 & 8.2 & 8.2 & 11.0 & 12.3 & 14.3 & 14.3 & 14.9 & 15.7 & 18.6 & 19.0 & 19.6 \\
\hline Soybean meal & 16.2 & 15.6 & 16.7 & 17.2 & 17.2 & 15.2 & 15.2 & 15.5 & 15.2 & 15.2 & 17.1 & 17.2 \\
\hline Wheat bran & 57.2 & 52.8 & 48.0 & 48.3 & 43.0 & 31.0 & 41.0 & 36.1 & 31.0 & 31.5 & 26.0 & 26.5 \\
\hline Fish oil & 5.2 & 9.1 & 12.8 & 3.5 & 7.5 & 12.0 & 2.0 & 5.8 & 9.8 & 1.5 & 4.7 & 8.5 \\
\hline Vit.Min.Mix. ${ }^{1}$ & 2.0 & 2.0 & 2.0 & 2.0 & 2.0 & 2.0 & 2.0 & 2.0 & 2.0 & 2.0 & 2.0 & 2.0 \\
\hline \multicolumn{13}{|c|}{ Proximate analysis (\% ww basis) } \\
\hline Crude protein & 25.12 & 24.87 & 24.88 & 30.1 & 30.09 & 29.86 & 34.87 & 34.83 & 34.87 & 39.54 & 39.89 & 39.59 \\
\hline Either extract & 8.33 & 12.18 & 15.79 & 7.12 & 11.07 & 14.89 & 6.21 & 9.94 & 13.91 & 6.20 & 9.31 & 13.61 \\
\hline Nitrogen free extract & 39.6 & 36.80 & 34.16 & 35.0 & 31.07 & 29.21 & 30.26 & 27.42 & 24.38 & 24.92 & 22.32 & 18.70 \\
\hline Energy of crude protein & 6.0 & 5.94 & 5.95 & 7.19 & 7.19 & 7.13 & 8.33 & 8.32 & 8.33 & 9.45 & 9.53 & 9.46 \\
\hline Energy of either extract & 3.31 & 4.85 & 6.28 & 2.83 & 4.40 & 5.93 & 2.47 & 3.96 & 5.54 & 2.47 & 3.70 & 5.42 \\
\hline Energy of NFE & 6.97 & 6.48 & 6.01 & 6.16 & 5.47 & 5.14 & 5.32 & 4.82 & 4.29 & 4.38 & 4.1 & 3.29 \\
\hline Total Gross energy $^{2}$ & 16.28 & 17.27 & 18.24 & 16.18 & 17.06 & 18.20 & 16.12 & 17.1 & 18.16 & 16.3 & 17.33 & 18.17 \\
\hline Fiber & 8.93 & 8.50 & 8.03 & 8.41 & 8.94 & 8.48 & 8.84 & 8.36 & 7.87 & 8.23 & 7.78 & 7.34 \\
\hline Ash & 9.56 & 9.57 & 9.45 & 9.97 & 10.02 & 9.90 & 11.38 & 11.32 & 11.33 & 12.80 & 12.73 & 12.65 \\
\hline Moisture & 8.46 & 8.08 & 7.69 & 9.40 & 8.81 & 7.66 & 8.44 & 8.13 & 7.64 & 8.31 & 7.97 & 8.11 \\
\hline Energy of CP/Total GE & 36.85 & 34.39 & 32.62 & 44.44 & 42.14 & 39.17 & 51.67 & 48.65 & 45.87 & 57.97 & 54.99 & 52.06 \\
\hline $\begin{array}{l}\text { Energy of Either } \\
\text { extract/Total GE }\end{array}$ & 20.33 & 28.08 & 34.43 & 17.49 & 25.79 & 32.58 & 15.32 & 23.16 & 30.51 & 15.15 & 21.35 & 29.83 \\
\hline Energy of NFE/Total GE & 42.81 & 37.52 & 32.95 & 38.07 & 32.06 & 28.4 & 33.0 & 28.19 & 23.62 & 26.87 & 23.66 & 18.11 \\
\hline $\mathrm{P} / \mathrm{E}(\mathrm{MJ})$ & 15.43 & 14.40 & 13.64 & 18.60 & 17.64 & 16.42 & 21.63 & 20.37 & 19.20 & 24.26 & 23.02 & 21.79 \\
\hline
\end{tabular}

1-Vitamin-mineral mixture: vitamin A, 600IU, vitamin D, 120IU, vitamin E, 78,000 mg; vitamin K, 25,000mg; vitamin B1, 12,000mg; vitamin B3, 32,000mg, vitaminB6, 21,000mg, b12vitamin, 110mg, vitamin D, 61,000mg, niacin, 210,000mg, folic acid, 400mg, biotin, $0.237 \mathrm{mg}$, selenium, $0.21 \mathrm{~g}$, iron, $82 \mathrm{~g}$, manganese, $90 \mathrm{~g}$; zinc, $70 \mathrm{~g}$, copper, $15 \mathrm{~g}$, potassium chloride, $4 \mathrm{~g}$;manganese oxide, $0.6 \mathrm{~g}$,sodium bicarbonate, $1.8 \mathrm{~g}$, Iodine, $1.2 \mathrm{~g}$, cobalt, $0.35 \mathrm{~g}$.

2-Gross energy ( $\mathrm{MJ} / \mathrm{kg}^{-1}$ diet) was calculated by using the following calorific values: 23.9, 39.8 and $17.6 \mathrm{kj} / \mathrm{g}^{-1}$ diet for protein, either extract and nitrogen free extract, respectively (NRC, 2011).

\section{Proximate analysis}

Before the experiment, 10 fish from the initial fish were randomly taken to determine initial body proximate composition. After the end of the experimental, fish were starved for $24 \mathrm{~h}$ prior to sample collection. Ten fish samples from each replicate were collected to determine the final proximate composition. Analyses of diets and fish tissues composition were done by (AOAC,2006), dry matter determined by drying samples in an oven at $105^{\circ} \mathrm{C}$ until constant weight; crude protein was measuring nitrogen by $(\mathrm{N} \times 6.25)$ after acid digestion (Kjeldahl method); crude lipid 
was determined through petroleum ether extraction using the (Soxhlet method), ash was detected by incineration in a furnace muffle at $550^{\circ} \mathrm{C}$ for $16 \mathrm{~h}$, while nitrogen free extract (NFE) was calculated by difference. Fish were collectively weighed every 2 weeks, and the amount of diet in restricted fed groups was adjusted accordingly. Following overnight fasting, 10 fish at the beginning, and after18 weeks were individually weight sacrificed to determine the proximate body composition including moisture, protein, ether extract and ash content following the (AOAC, 2006) methods. Total mortalities were recorded from each tank daily. Gross energy of body tissue $\left(\mathrm{MJ} / \mathrm{Kg}^{-1}\right.$ diet) was calculated by using the following calorific values: $23.9,39.8$ and $17.6 \mathrm{KJ} / \mathrm{g}^{-1}$ diet for protein, ether extract and nitrogen free extract, respectively (NRC, 2011).

\section{Performance induces}

The performance of the experimental fish was calculated using the following equations:

Weight gain $(\mathrm{g})=$ (Final body weight-Initial body weight).

Feed conversion ratio $(\mathrm{FCR})=$ Feed intake $(\mathrm{g}) /$ Weight gain $(\mathrm{g})$.

Feed efficiency $(\mathrm{FE} \%)=($ weight gain $\%) /$ Feed intake (dry matter)

Protein efficiency ratio (PER \%) = Fish weight gain $(\mathrm{g}) /$ Protein intake $(\mathrm{g})$.

Specific growth rate $(\mathrm{SGR}, \%$ day $)=(\mathrm{Ln}$ FBW- Ln IBW $) / \mathrm{t} \times 100$; where: FBW is final body weight $(\mathrm{g})$; IBW is initial body weight $(\mathrm{g})$; $\mathrm{Ln}=$ natural logarithmic; $\mathrm{t}=$ time in days.

Protein intake $=($ Feed intake $(\mathrm{g}) \times$ Protein in the diet $\%)$.

Feed conversion efficiency (FCE \%) $=100 \times$ (final body weight-initial body weight)/feed intake.

Protein retained $(\%)=($ Protein deposition in final muscle fish - Protein deposition in initial muscle)/Protein intake $\times 100$.

\section{Statistical Analysis}

All data are presented as mean \pm SD. Data were statistically analyzed by two way classification ANOVA (factorials design) using SPSS (version 16.0, 2016). Duncan's multiple range test was used to compare differences between treatment means when significant $\mathrm{F}$ values were observed (Duncan, 1955), at $P \leq 0.05$ level. The relationship between growth and feed utilization indices was tested using correlation analysis.

\section{RESULTS AND DISCUSSION}

The combined effects of dietary both protein levels and energy levels on growth performance are shown in (Table, 2). With all treatments, a significant and progressive increase $(P<0.05)$ of final body weight was recorded with the increase of protein levels from 25 up to $35 \%$, irrespective of dietary energy levels. However, irrespective of dietary protein levels increasing dietary energy levels (from 16 to18 $\mathrm{MJ} / \mathrm{Kg}$ diet) obtained slightly final body weight gain. The interaction between protein and energy levels showed a significant $(\mathrm{P}<0.05)$ effect of on final body weight with highly correlation values $\left(\mathrm{R}^{2}=0.82\right.$, Fig. 1$)$. Considering the effect of dietary protein energy ratios on final body weight, recorded the highest final body weight $(P<0.05)$ values for fish fed $30 \%$ crude protein with $18 \mathrm{MJ} / \mathrm{Kg}$ diet. The same trend was observed either the effect of dietary energy levels irrespective dietary protein level (Fig. 2 a) or vice versa (Fig. 2b). Similar results were obtained for trout Rainbow trout (Sanchez-Vazquez et al., 1998 and 1999). 


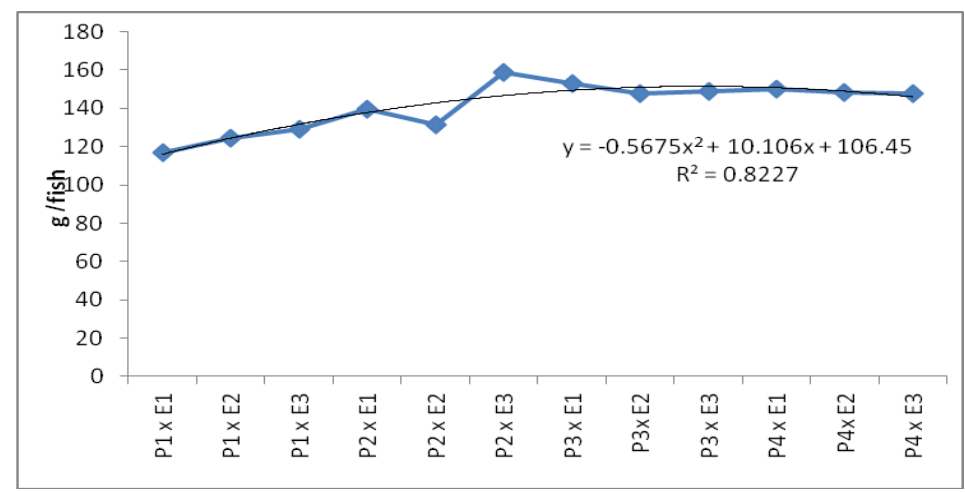

Fig. 1: The correlation between the interaction effect of dietary protein and energy levels and fish final body weight.

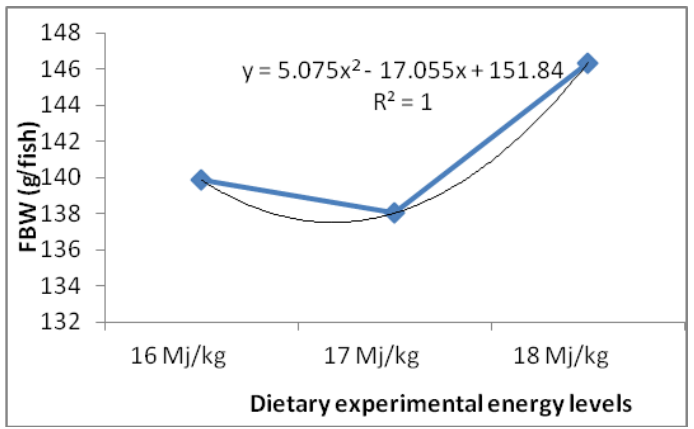

A

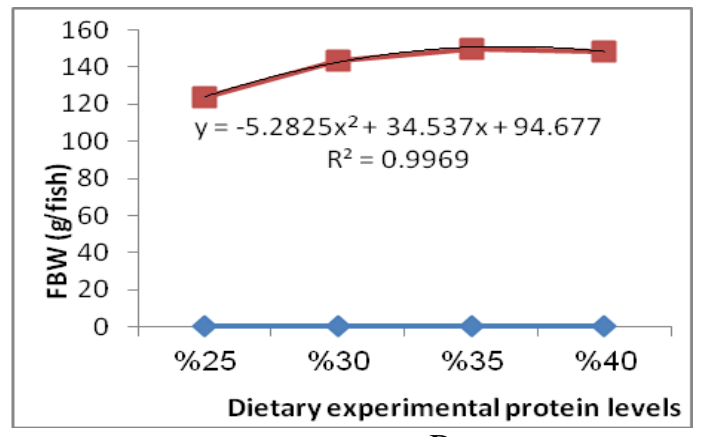

B

Fig. 1: The correlation between the effect of dietary protein (a) and energy levels (B) irrespective each other and fish final body weight.
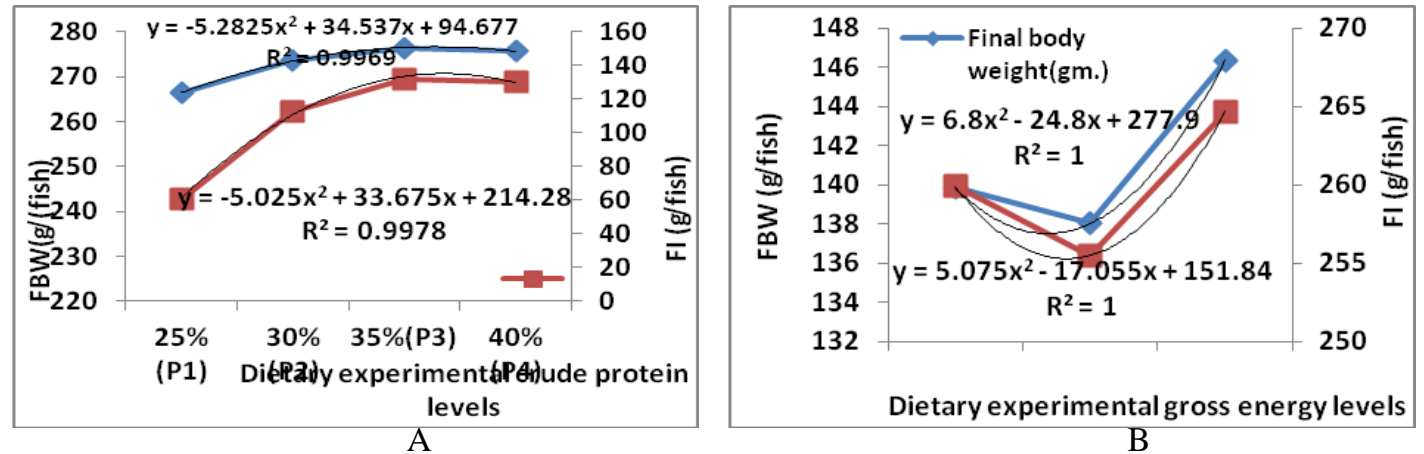

Fig. 2: The correlation between the effect of dietary protein (a) and energy levels (B) irrespective each other with fish final body weight against feed intake.

Though, the most optimal growth performance (Table, 2) in this experiment resulted in both treats contained $\left(30 \%\right.$ crude protein vs. $18 \mathrm{KJ} \mathrm{g}^{-1}$ diet and $35 \%$ crude protein vs. $16 \mathrm{KJ} \mathrm{g}^{-1}$ ) compare with the other treatments. While, growth performance was significantly reduced $(\mathrm{P}<0.05)$ in the present experiment when the protein content of the diet was lower than $30 \%$ irrespective of dietary energy level. The mentioned effect, seemed to be related to the high carbohydrate levels in $25 \%$ diet (Table, 1), which led to decreased growth performance as reported by (Helland and Helland,1997). In the same manner, previous researches recorded that carbohydrate utilization differently among species (Wilson, 1994, Hemer et al., 2002 and Krogdahl et al.,2005). Where, herbivorous or omnivorous fish species, such as grass carp, Ctenophoryngodon idella (Lin, 1991) and Nile tilapia, Oreochromis niloticus $\times$ O. aures (Shiau and Peng, 1993), showed better metabolic synthesis of carbohydrate than cold water. In contrast, marine carnivorous fish species, such as Atlantic salmon, Salmo salar (Helland et al., 1991) and Yellowtail, Seriloa quinqueradiata (Shimeno, 
1991) had a less ability to use carbohydrates in their diets. The different efficiency for carbohydrate synthesis between species, due to their natural habitat, longer digestive tract and the activity of digestive tract.

Table 2: Growth performance of mullets fingerling, Mugil cephalus fed the experimental diets for 18 weeks.

\begin{tabular}{|c|c|c|c|c|c|c|}
\hline \multicolumn{2}{|c|}{$\begin{array}{l}\text { Dietary Crude } \\
\text { protein }(\%, \mathrm{CP})\end{array}$} & \multirow{2}{*}{$\begin{array}{c}\begin{array}{c}\text { Initial body } \\
\text { weight (gm.) }\end{array} \\
30.31 \pm 2.51\end{array}$} & \multirow{2}{*}{$\begin{array}{l}\begin{array}{l}\text { Final body } \\
\text { weight (gm.) }\end{array} \\
123.67^{\mathrm{c}} \pm 6.3\end{array}$} & \multirow{2}{*}{$\begin{array}{l}\text { Gain weight } \\
\text { (gm.) }\end{array}$} & \multirow{2}{*}{$\begin{array}{l}\text { Specific growth } \\
\text { rate (\%/day) } \\
1.11^{\mathrm{b}} \pm 0.16\end{array}$} & \multirow{2}{*}{$\begin{array}{l}\text { Percentage } \\
\text { Weight Gain }(\%) \\
308.15^{\mathrm{c}} \pm 3.98\end{array}$} \\
\hline 25 & P1 & & & & & \\
\hline 30 & $\mathrm{P} 2$ & $30.62 \pm 2.03$ & $143.41^{\mathrm{b}} \pm 9.5$ & $112.79^{\mathrm{b}} \pm 8.5$ & $1.22^{\mathrm{a}} \pm 0.14$ & $368.35^{\mathrm{b}} \pm 4.41$ \\
\hline 35 & P3 & $30.11 \pm 2.33$ & $149.96^{\mathrm{ab}} \pm 2.7$ & $119.85^{\mathrm{b}} \pm 2.3$ & $1.28^{\mathrm{a}} \pm 0.17$ & $398.04^{\mathrm{b}} \pm 22.55$ \\
\hline 40 & P4 & $29.9 \pm 2.47$ & $148.57^{\mathrm{ab}} \pm 2.8$ & $118.67^{b} \pm 2.6$ & $1.27^{\mathrm{a}} \pm 0.11$ & $396.89^{b} \pm 12.2$ \\
\hline \multicolumn{7}{|c|}{ Gross energy levels $\left(\mathrm{KJ} / \mathrm{g}^{-1}\right)$} \\
\hline 16 & E1 & $29.25 \pm 1.8$ & $139.86^{\mathrm{b}} \pm 13.5$ & $110.61^{\mathrm{b}} \pm 11.26$ & $1.24^{\mathrm{a}} \pm 0.13$ & $378.15^{\mathrm{b}} \pm 51.19$ \\
\hline 17 & E2 & $30.31 \pm 2.3$ & $138.03^{\mathrm{b}} \pm 11.8$ & $107.72^{\mathrm{b}} \pm 12.13$ & $1.20^{\mathrm{a}} \pm 0.15$ & $355.39^{\mathrm{b}} \pm 47.16$ \\
\hline 18 & E3 & $31.16 \pm 2.5$ & $146.35^{\mathrm{ab}} \pm 12.2$ & $115.19^{\mathrm{ab}} \pm 11.36$ & $1.23^{\mathrm{a}} \pm 0.16$ & $369.67^{\mathrm{b}} \pm 42.25$ \\
\hline \multicolumn{7}{|c|}{ Protein levels $(\%) \times$ Gross energy levels $\left(\mathrm{KJ} / \mathrm{g}^{-1}\right)$} \\
\hline $\mathrm{P} 1 \times$ & & $28.88 \pm 2.72$ & $117.16^{\mathrm{c}} \pm 4.2$ & $88.28 \mathrm{c} \pm 4.5$ & $1.11^{\mathrm{b}} \pm 0.15$ & $305.68^{c} \pm 51.9$ \\
\hline $\mathrm{P} 1 \times$ & & $30.58 \pm 2.95$ & $124.54^{\mathrm{b}} \pm 4.9$ & $93.96^{\mathrm{c}} \pm 5.3$ & $1.11^{\mathrm{b}} \pm 0.13$ & $307.26^{\mathrm{c}} \pm 47.16$ \\
\hline $\mathrm{P} 1 \times$ & & $31.43 \pm 3.01$ & $129.38^{\mathrm{b}} \pm 7.7$ & $97.95^{\mathrm{c}} \pm 6.8$ & $1.12^{\mathrm{b}} \pm 0.10$ & $311.64^{\mathrm{c}} \pm 42.25$ \\
\hline $\mathrm{P} 2 \times$ & & $29.52 \pm 2.41$ & $139.82^{\mathrm{b}} \pm 5.1$ & $110.30^{\mathrm{b}} \pm 5.3$ & $1.23^{\mathrm{a}} \pm 0.17$ & $373.64^{\mathrm{b}} \pm 12.5$ \\
\hline $\mathrm{P} 2 \times$ & & $31.15 \pm 2.88$ & $131.46^{\mathrm{b}} \pm 6.9$ & $100.31^{\mathrm{b}} \pm 6.1$ & $1.15^{\mathrm{b}} \pm 0.10$ & $322.02^{\mathrm{c}} \pm 18.2$ \\
\hline $\mathrm{P} 2 \times$ & & $31.18 \pm 3.14$ & $158.96^{\mathrm{a}} \pm 6.8$ & $127.78^{a} \pm 5.7$ & $1.29^{\mathrm{a}} \pm 0.23$ & $409.81^{\mathrm{a}} \pm 15.3$ \\
\hline $\mathrm{P} 3 \times$ & & $29.16 \pm 2.25$ & $152.94^{\mathrm{ab}} \pm 6.5$ & $123.78^{a} \pm 6.3$ & $1.32^{\mathrm{a}} \pm 0.18$ & $424.38^{\mathrm{a}} \pm 19.2$ \\
\hline $\mathrm{P} 3 \times$ & & $30.34 \pm 2.69$ & $147.73^{\mathrm{ab}} \pm 5.3$ & $117.39^{\mathrm{ab}} \pm 5.7$ & $1.26^{\mathrm{a}} \pm 0.12$ & $385.78^{\mathrm{b}} \pm 18.6$ \\
\hline $\mathrm{P} 3 \times$ & & $30.77 \pm 2.40$ & $149.20^{\mathrm{ab}} \pm 6.3$ & $118.43^{\mathrm{ab}} \pm 5.4$ & $1.25^{\mathrm{a}} \pm 0.19$ & $384.89^{\mathrm{b}} \pm 13.3$ \\
\hline $\mathrm{P} 4 \times$ & & $29.74 \pm 2.87$ & $149.94^{\mathrm{ab}} \pm 7.6$ & $120.20^{\mathrm{a}} \pm 6.8$ & $1.28^{\mathrm{a}} \pm 0.21$ & $404.17^{\mathrm{a}} \pm 14.9$ \\
\hline $\mathrm{P} 4 \times$ & & $29.44 \pm 2.25$ & $148.25^{\mathrm{ab}} \pm 5.7$ & $118.81^{\mathrm{a}} \pm 5.3$ & $1.28^{\mathrm{a}} \pm 0.14$ & $403.57^{\mathrm{a}} \pm 18.6$ \\
\hline $\mathrm{P} 4 \times$ & & $30.55 \pm 2.91$ & $147.48^{\mathrm{ab}} \pm 4.5$ & $116.93^{\mathrm{ab}} \pm 4.9$ & $1.25^{\mathrm{a}} \pm 0.13$ & $382.75^{\mathrm{a} b} \pm 15.2$ \\
\hline
\end{tabular}

Values with different superscripts letters are significantly different $(p<0.05)$.

The results presented in (Table, 3) indicated that feed intake was varies between fish fed the same amount of energy level, where it's increased with increasing dietary protein levels from 25 to $35 \%$ especially for fish fed the diets contained either 16 or $18 \mathrm{~kJ} / \mathrm{g}$ energy levels. Feed conversion ratio was ranged between 2.18 and 2.67.

The current study showed that with increasing FBW the feed intake was increased either the effect of dietary energy levels irrespective dietary protein level $\left(\mathrm{R}^{2}=1\right.$ Fig. 2 a) or vice versa $\left(\mathrm{R}^{2}=1\right.$ Fig. $\left.2 \mathrm{~b}\right)$ with highly correlation values against feed intake (FBW: $\mathrm{R}^{2}=0.53$, FI: $\mathrm{R}^{2}=0.82$, Fig. 3 ). The interaction between protein and energy levels showed a significant $(P<0.05)$ effect on final body weight with moderate correlation values against feed intake (FBW: $\mathrm{R}^{2}=0.53$, FI: $\mathrm{R}^{2}=0.82$ Fig. 3 ). Those results may attribute to the increase of palatability of diets with addition a higher levels of oil as energy sources which making it more attractive to the fish especially for dietary moderate crude protein levels (30-35\%).

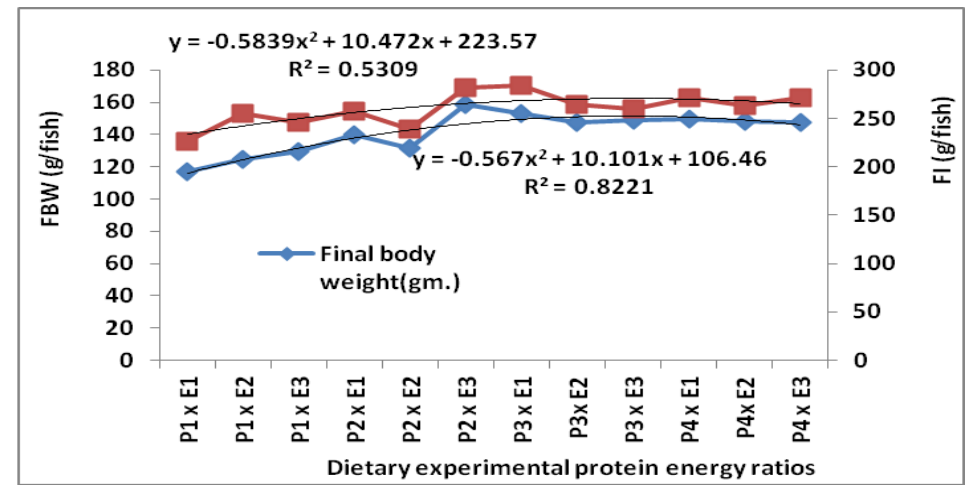

Fig. 3: The correlation between the interaction effect of dietary protein and energy levels with fish final body weight against feed intake. 
A similar result was reported by (Montero et al., 2005). In this connection, (Klaoudatos et al., 2005) observed the higher feed intake values with lower dietary energy-high protein diet compared with the higher dietary energy-high protein for sea bream, Sparus aurata which indicating that regulation of the feed intake was secondarily to the dietary energy content, as observed in the present study (Figs. 3-4).

Table 3: Feed efficiency and (protein \& energy) retention of fingerling, Mugil cephalus fed experimental diets for 18 weeks.

\begin{tabular}{|c|c|c|c|c|c|c|}
\hline \multicolumn{2}{|c|}{ Treatment } & \multirow[t]{2}{*}{ Feed intake } & \multirow[t]{2}{*}{ FCR } & \multirow[t]{2}{*}{ FCE } & \multirow[t]{2}{*}{ Protein retained } & \multirow[t]{2}{*}{ Energy retained } \\
\hline \multicolumn{2}{|c|}{ Protein levels $(\%)$} & & & & & \\
\hline 25 & $\mathrm{P} 1$ & $242.7^{b} \pm 14.6$ & $2.60^{\mathrm{b}} \pm 0.11$ & $38.48^{\mathrm{b}} \pm 1.6$ & $24.92^{\mathrm{a}} \pm 1.07$ & $61.16^{\mathrm{b}} \pm 3.11$ \\
\hline 30 & $\mathrm{P} 2$ & $262.2^{\mathrm{a}} \pm 15.7$ & $2.32^{\mathrm{a}} \pm 0.10$ & $43.02^{\mathrm{a}} \pm 1.8$ & $23.14^{\mathrm{a}} \pm 0.66$ & $69.52^{\mathrm{a}} \pm 2.45$ \\
\hline 35 & P3 & $269.4^{\mathrm{a}} \pm 12.7$ & $2.25^{\mathrm{a}} \pm 0.10$ & $44.49^{\mathrm{a}} \pm 1.3$ & $19.56^{\mathrm{b}} \pm 0.79$ & $72.32^{\mathrm{a}} \pm 2.46$ \\
\hline 40 & $\mathrm{P} 4$ & $268.8^{\mathrm{a}} \pm 4.2$ & $2.26^{\mathrm{a}} \pm 0.10$ & $44.15^{\mathrm{a}} \pm 1.3$ & $18.10^{\mathrm{b}} \pm 1.82$ & $70.89^{a} \pm 3.82$ \\
\hline \multicolumn{7}{|c|}{ Gross energy levels $\left(\mathrm{KJ} / \mathrm{g}^{-1}\right)$} \\
\hline 16 & E1 & $259.9 \pm 24.6$ & $2.35^{\mathrm{a}} \pm 0.12$ & $42.56^{\mathrm{a}} \pm 2.3$ & $21.86^{\mathrm{b}} \pm 3.2$ & $72.06^{\mathrm{a}} \pm 3.75$ \\
\hline 17 & $\mathrm{E} 2$ & $255.5 \pm 11.7$ & $2.37^{\mathrm{a}} \pm 0.18$ & $42.16^{\mathrm{a}} \pm 3.5$ & $21.00^{\mathrm{b}} \pm 2.8$ & $67.10^{\mathrm{a}} \pm 3.05$ \\
\hline 18 & E3 & $264.7 \pm 15.3$ & $2.30^{\mathrm{a}} \pm 0.13$ & $43.52^{\mathrm{a}} \pm 2.1$ & $21.43^{\mathrm{b}} \pm 3.4$ & $66.27^{\mathrm{b}} \pm 4.1$ \\
\hline \multicolumn{7}{|c|}{ Protein levels $(\%) \times$ Gross energy levels $\left(\mathrm{KJ} / \mathrm{g}^{-1}\right)$} \\
\hline $25 \times$ & & $226.8^{c} \pm 7.5$ & $2.57^{\mathrm{b}} \pm 0.11$ & $38.92^{\mathrm{b}} \pm 1.8$ & $25.79^{\mathrm{a}} \pm 1.62$ & $66.95^{\mathrm{b}} \pm 3.17$ \\
\hline $25 x$ & & $255.3^{\mathrm{b}} \pm 9.7$ & $2.72^{\mathrm{b}} \pm 0.12$ & $36.80^{\mathrm{b}} \pm 1.5$ & $23.72^{\mathrm{a}} \pm 1.57$ & $57.24^{\mathrm{c}} \pm 2.80$ \\
\hline $25 x$ & & $246.0^{\mathrm{bc}} \pm 11.9$ & $2.51^{\mathrm{b}} \pm 0.14$ & $39.82^{\mathrm{b}} \pm 1.7$ & $25.25^{\mathrm{a}} \pm 1.36$ & $59.29^{c} \pm 3.10$ \\
\hline $30 \times$ & & $257.5^{\mathrm{b}} \pm 9.2$ & $2.33^{\mathrm{a}} \pm 0.11$ & $42.92^{\mathrm{a}} \pm 1.6$ & $22.83^{\mathrm{a}} \pm 1.43$ & $71.53^{\mathrm{a}} \pm 2.7$ \\
\hline $30 \times$ & & $239.1^{\mathrm{c}} \pm 11.0$ & $2.38^{\mathrm{a}} \pm 0.09$ & $41.95^{\mathrm{b}} \pm 1.2$ & $22.69^{\mathrm{a}} \pm 1.72$ & $66.79^{\mathrm{b}} \pm 2.15$ \\
\hline $30 \times$ & & $281.9^{\mathrm{a}} \pm 10.2$ & $2.21^{\mathrm{a}} \pm 0.10$ & $45.33^{\mathrm{a}} \pm 1.6$ & $23.90^{\mathrm{a}} \pm 1.64$ & $70.25^{\mathrm{b}} \pm 2.1$ \\
\hline $35 x$ & & $283.9^{\mathrm{a}} \pm 11.1$ & $2.29^{\mathrm{a}} \pm 0.08$ & $43.60^{\mathrm{a}} \pm 1.5$ & $18.66^{\mathrm{b}} \pm 1.56$ & $74.90^{\mathrm{a}} \pm 3.2$ \\
\hline $35 x$ & & $264.0^{\mathrm{ab}} \pm 13.4$ & $2.25^{\mathrm{a}} \pm 0.06$ & $44.57^{\mathrm{a}} \pm 1.2$ & $20.14^{\mathrm{b}} \pm 1.71$ & $72.07^{\mathrm{a}} \pm 3.6$ \\
\hline $35 x$ & & $259.9^{\mathrm{b}} \pm 12.2$ & $2.19^{\mathrm{a}} \pm 0.10$ & $45.57^{\mathrm{a}} \pm 1.8$ & $19.88^{\mathrm{b}} \pm 1.63$ & $70.00^{\mathrm{a}} \pm 2.9$ \\
\hline $40 x$ & & $271.6^{\mathrm{a}} \pm 10.4$ & $2.26^{\mathrm{a}} \pm 0.07$ & $44.26^{\mathrm{a}} \pm 1.9$ & $20.15^{\mathrm{b}} \pm 1.59$ & $74.85^{\mathrm{a}} \pm 2.1$ \\
\hline $40 \times$ & & $263.3^{\mathrm{ab}} \pm 11.8$ & $2.22^{\mathrm{a}} \pm 0.09$ & $45.12^{\mathrm{a}} \pm 1.4$ & $17.44^{\mathrm{b}} \pm 1.81$ & $72.29^{\mathrm{a}} \pm 3.0$ \\
\hline $40 x$ & & $270.8^{a} \pm 10.6$ & $2.32^{\mathrm{a}} \pm 0.10$ & $43.18^{\mathrm{a}} \pm 1.6$ & $16.70^{\mathrm{b}} \pm 1.69$ & $62.52^{\mathrm{b}} \pm 2.3$ \\
\hline
\end{tabular}

Values with different superscripts letters are significantly different $(p<0.05)$.

Table 4: Muscle body composition (ww/basis) of Mugil cephalus fed the experimental diets for 18 weeks.

\begin{tabular}{|c|c|c|c|c|c|}
\hline Composition & Moisture \% & Crude protein $\%$ & Ether extract \% & Ash & Gross EnergyKJ/g \\
\hline Initial & $68.14 \pm 1.37$ & $16.93 \pm 0.87$ & $11.45 \pm 0.51$ & $3.48 \pm 0.63$ & $26.85 \pm 1.24$ \\
\hline \multicolumn{6}{|c|}{ Final protein levels $(\%)$. } \\
\hline $\mathrm{P} 1$ & $67.04 \pm 1.16$ & $16.34 \pm 0.83$ & $12.63^{\mathrm{b}} \pm 0.35$ & $4.31 \pm 0.26$ & $26.96 \pm 1.42$ \\
\hline $\mathrm{P} 2$ & $66.17 \pm 1.48$ & $16.21 \pm 0.63$ & $13.43^{\mathrm{a}} \pm 0.47$ & $4.34 \pm 0.23$ & $27.12 \pm 1.53$ \\
\hline P3 & $65.61 \pm 1.37$ & $15.63 \pm 0.70$ & $14.15^{\mathrm{a}} \pm 0.33$ & $4.50 \pm 0.31$ & $27.11 \pm 1.38$ \\
\hline P4 & $65.72 \pm 1.52$ & $16.09 \pm 0.61$ & $13.87^{\mathrm{a}} \pm 0.38$ & $4.32 \pm 0.25$ & $27.18 \pm 1.41$ \\
\hline \multicolumn{6}{|c|}{ Gross energy levels $\left(\mathrm{KJ} / \mathrm{g}^{-1}\right)$} \\
\hline E1 & $66.14 \pm 1.74$ & $16.26 \pm 0.86$ & $13.43^{\mathrm{a}} \pm 0.62$ & $4.42 \pm 0.21$ & $27.12 \pm 1.32$ \\
\hline E2 & $66.05 \pm 1.88$ & $16.11 \pm 0.71$ & $13.34^{\mathrm{a}} \pm 0.73$ & $4.42 \pm 0.27$ & $26.85 \pm 1.24$ \\
\hline E3 & $66.23 \pm 1.65$ & $15.85 \pm 0.62$ & $13.78^{\mathrm{a}} \pm 0.74$ & $4.27 \pm 0.19$ & $27.32 \pm 1.35$ \\
\hline \multicolumn{6}{|c|}{ Protein levels $(\%) \times$ Gross energy levels $\left(\mathrm{KJ} / \mathrm{g}^{-1}\right)$} \\
\hline $25 \times 16$ & $66.91 \pm 1.80$ & $16.71 \pm 0.98$ & $12.89^{\mathrm{b}} \pm 0.71$ & $4.49 \pm 0.33$ & $27.42 \pm 2.17$ \\
\hline $25 \times 17$ & $67.22 \pm 1.55$ & $16.25 \pm 0.73$ & $12.27^{\mathrm{b}} \pm 0.49$ & $4.26 \pm 0.41$ & $26.60 \pm 1.95$ \\
\hline $25 \times 18$ & $67.00 \pm 1.62$ & $16.07 \pm 0.86$ & $12.74^{\mathrm{b}} \pm 0.52$ & $4.19 \pm 0.32$ & $26.86 \pm 2.29$ \\
\hline $30 \times 16$ & $66.38 \pm 1.52$ & $16.23 \pm 0.72$ & $12.91^{\mathrm{b}} \pm 0.57$ & $4.48 \pm 0.53$ & $26.67 \pm 2.05$ \\
\hline $30 \times 17$ & $65.63 \pm 2.05$ & $16.43 \pm 0.69$ & $13.57^{\mathrm{a}} \pm 0.65$ & $4.37 \pm 0.37$ & $26.99 \pm 2.49$ \\
\hline $30 \times 18$ & $66.51 \pm 1.70$ & $15.98 \pm 0.73$ & $13.82^{\mathrm{a}} \pm 0.71$ & $4.18 \pm 0.49$ & $27.69 \pm 1.98$ \\
\hline $35 \times 16$ & $66.11 \pm 1.68$ & $15.31 \pm 0.76$ & $14.11^{\mathrm{a}} \pm 0.51$ & $4.47 \pm 0.36$ & $27.23 \pm 2.03$ \\
\hline $35 \times 17$ & $65.18 \pm 2.02$ & $16.02 \pm 0.88$ & $13.85^{\mathrm{a}} \pm 0.42$ & $4.65 \pm 0.55$ & $26.69 \pm 1.76$ \\
\hline $35 \times 18$ & $65.55 \pm 1.87$ & $15.57 \pm 0.94$ & $14.50^{\mathrm{a}} \pm 0.40$ & $4.38 \pm 0.51$ & $27.42 \pm 2.14$ \\
\hline $40 \times 16$ & $65.14 \pm 2.05$ & $16.80 \pm 0.83$ & $13.81^{\mathrm{a}} \pm 0.44$ & $4.25 \pm 0.36$ & $27.14 \pm 2.05$ \\
\hline $40 \times 17$ & $66.16 \pm 1.89$ & $15.72 \pm 0.74$ & $13.73^{\mathrm{a}} \pm 0.72$ & $4.39 \pm 0.44$ & $27.11 \pm 1.86$ \\
\hline $40 \times 18$ & $85.86 \pm 1.73$ & $15.76 \pm 0.80$ & $14.70^{\mathrm{a}} \pm 0.89$ & $4.31 \pm 0.39$ & $27.30 \pm 2.11$ \\
\hline
\end{tabular}

Values with different superscripts letters are significantly different $(p<0.05)$ 
In the present study it's clear the effect of dietary energy value for proteinsparing effect in the tested diets. So, the highest growth observed with fish fed 30\% crude protein and $18 \mathrm{~kJ} / \mathrm{g}$ dietary energy may regarding to increasing dietary lipid content up to $(14.89 \%)$ in the above diet (Table 1). The same finding was reported by Verger et al. (1996) observed a protein- sparing effect by increased dietary lipid from 9 to $15 \%$ in sea bream Sparus aurata and from 4-16 in sole, Solea aegyptiaca diets (Yones et al., 2018). The same trend was found by (Caballero et al., 1999) for Sparus aurata when fish fed with $27 \%$ dietary lipid, resulted the highest fish growth compared to fish fed diets contained 22 and $15 \%$ lipid. The decreased in fish growth when fed $15 \%$ lipid, could be insufficient level to cover energy requirements and this leading to a subsequent using dietary protein for supplied energy. Moreover, (Boujard and Medale, 1994 and Woods et al., 1998) explain the correlation between body weight and feed intake. They noticed that the predicts secretions from fat cells are the key signal to the brain to regulate feeding and body-fat deposition. A feedback regulatory loop with distinct steps has been hypothesized, which include a sensor monitors energy levels, hypothalamic centers that receive and integrate through lepton receptors the intensity of the signal and effector systems that influence energy intake and expenditure (Jequier and Tappy, 1999). Though, (Pitcher and Hart,1982) showed that the ecologically important feature of digestion is the rate at which food can be processed and this determine the upper limit to intake energy and hence the upper limit of growth.

In the present study, FCR values decreased $(P \geq 0.05)$ either with increasing dietary crude protein irrespective of dietary energy levels (Fig. $4, R^{2}=0.99$ ) or dietary energy levels irrespective of dietary crude protein levels (Fig. 5, $\mathrm{R}^{2}=1$ ). The best FCR value was obtained with dietary energy $18 \mathrm{Mj} \mathrm{kg}^{-1}$ and $30 \%$ protein, followed by higher FBW and, WG compared to those fed the other diets may be due to the enhancement effect of $\mathrm{P} / \mathrm{E}$ ratio on utilization and digestibility of diet.

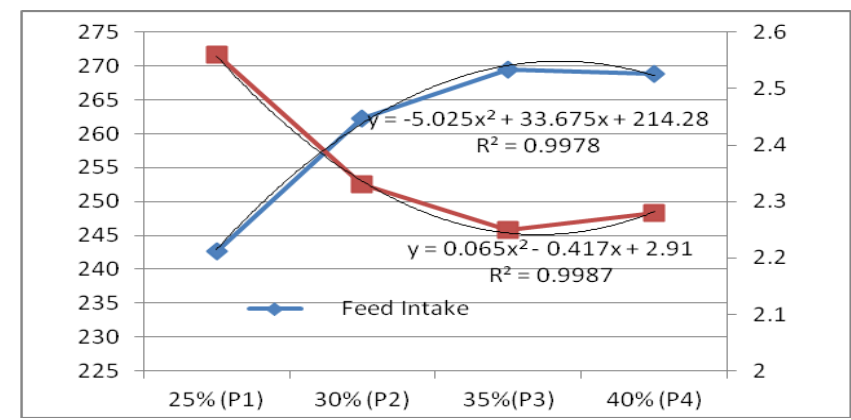

Fig. 4: The correlation between the effect of dietary protein irrespective of dietary energy levels with FCR against feed intake.

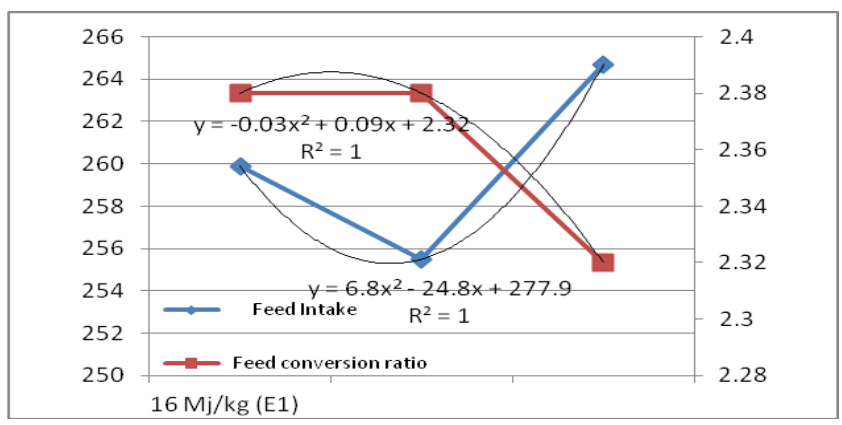

Fig. 5: The correlation between the effect of dietary energy levels irrespective of dietary protein levels with FCR against feed intake. 
No statistical differences $(P>0.05)$ was observed for the influence of dietary protein energy ratios on whole body proximate analysis except for body ether extract contents (Table 4), The body lipid deposition may indicate that, when dietary lipid was supplied in excess, a proportion of this lipid was deposit as fats. The present results are agree with the results on mullet Liza ramada (Yones and Abdel-Tawab, 2005 and Yones et al., 2016), tilapia, Tilapia zilli, (El-Sayed and Garling, 1988) and trout, Salmo guirdneri (Austreng,1979).

Concomitant increase $(P<0.05)$ of body lipid and protein retained were observed with increase dietary lipid levels (Figs. 6-7), while negative effect on energy retained was recorded with increase energy levels (Table 5), may due to the proteinsparing effect of dietary lipid (Kaushik and Medale, 1994). Data presented here showed that Mugil cephalus tend to less lipid efficiency than protein. Comparable results were recorded in mullet Liza ramada (Yones and Abdel-Tawab, 2005 and Yones et al., 2016) and carp Common carp (Schwarz and Kirchgessner, 1995). However, the lipid deposition in fish depended to the source of energy, where its more deposit from lipid than carbohydrate sources as illustrated by (Emmans, 1994). Moreover, Lupatsch et al. (2003) assumed that at the highest protein-energy intake level, protein is used not just for protein deposition, but also as an energy source to deposit lipid, although at lower efficiency. The same authors showed that energy efficiency in fish would however decrease if dietary protein was used as an energy source beyond its main role for protein synthesis.

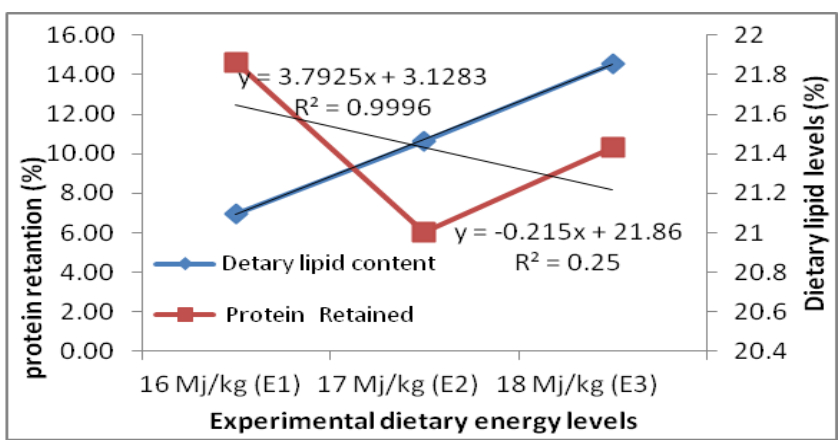

Fig. 6. The correlation between the effects of dietary energy levels irrespective of dietary protein levels on protein retained against dietary lipid levels.

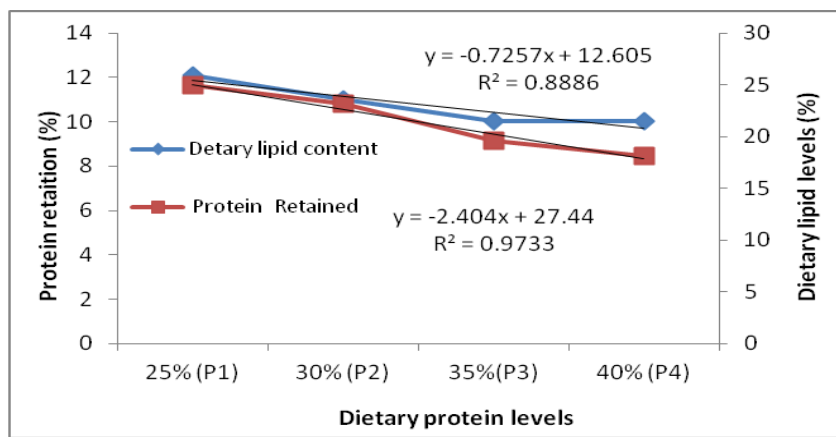

Fig. 7: The correlation between the effects of dietary protein levels irrespective of dietary energy levels on protein retained against dietary lipid levels. 
Table 5: Protein and energy efficiency ratio, protein deposition and lipid deposition and retention of Mugil cephalus fed experimental diets for 18 weeks.

\begin{tabular}{|c|c|c|c|c|c|c|}
\hline Parameters" & & PER & EER & $\mathrm{PD}$ & LD & LR \\
\hline \multicolumn{7}{|c|}{ Protein levels $(\%)$. } \\
\hline 25 & $\mathrm{P} 1$ & $1.54^{\mathrm{a}} \pm 0.06$ & $2.27^{b} \pm 0.14$ & $15.07^{\mathrm{c}} \pm 0.38$ & $9.77^{\mathrm{c}} \pm 0.13$ & $37.06^{\mathrm{b}} \pm 12.41$ \\
\hline 30 & $\mathrm{P} 2$ & $1.44^{\mathrm{a}} \pm 0.07$ & $2.56^{\mathrm{a}} \pm 0.14$ & $18.05^{\mathrm{b}} \pm 1.92$ & $12.66^{\mathrm{b}} \pm 2.15$ & $47.12^{\mathrm{b}} \pm 14.40$ \\
\hline 35 & P3 & $1.28^{\mathrm{b}} \pm 0.04$ & $2.61^{\mathrm{a}} \pm 0.10$ & $18.40^{\mathrm{b}} \pm 0.33$ & $14.48^{\mathrm{a}} \pm 0.77$ & $59.47^{\mathrm{b}} \pm 23.67$ \\
\hline 40 & $\mathrm{P} 4$ & $1.11^{\mathrm{b}} \pm 0.03$ & $2.60^{\mathrm{a}} \pm 0.19$ & $19.34^{\mathrm{b}} \pm 1.99$ & $13.01^{\mathrm{b}} \pm 1.70$ & $56.51^{\mathrm{b}} \pm 12.76$ \\
\hline \multicolumn{7}{|c|}{ Gross energy levels $\left(\mathrm{KJ} / \mathrm{g}^{-1}\right)$} \\
\hline 16 & E1 & $1.33^{\mathrm{b}} \pm 0.19$ & $2.65^{\mathrm{a}} \pm 0.15$ & $18.17^{\mathrm{b}} \pm 2.86$ & $11.89^{\mathrm{b}} \pm 2.33$ & $66.64^{\mathrm{a}} \pm 4.10$ \\
\hline 16 & E2 & $1.32^{\mathrm{b}} \pm 0.15$ & $2.48^{\mathrm{a}} \pm 0.22$ & $17.06^{\mathrm{b}} \pm 1.66$ & $12.07^{\mathrm{b}} \pm 2.05$ & $45.39^{\mathrm{b}} \pm 1.23$ \\
\hline 16 & E3 & $1.38^{\mathrm{b}} \pm 0.23$ & $2.42^{\mathrm{a}} \pm 0.15$ & $17.92^{\mathrm{b}} \pm 1.91$ & $13.76^{\mathrm{ab}} \pm 2.00$ & $35.87^{\mathrm{b}} \pm 5.40$ \\
\hline \multicolumn{7}{|c|}{ Protein levels $(\%) \times$ Gross energy levels $\left(\mathrm{KJ} / \mathrm{g}^{-1}\right)$. } \\
\hline $25 \times 16$ & & $1.55^{\mathrm{a}} \pm 0.14$ & $2.14^{\mathrm{b}} \pm 0.13$ & $14.69^{c} \pm 1.14$ & $9.68^{\mathrm{c}} \pm 0.38$ & $25.21^{\mathrm{c}} \pm 1.62$ \\
\hline $25 \times 17$ & & $1.68^{\mathrm{a}} \pm 0.09$ & $2.16^{\mathrm{b}} \pm 0.05$ & $15.06^{\mathrm{c}} \pm 0.78$ & $9.86^{\mathrm{c}} \pm 0.77$ & $31.90^{c} \pm 3.70$ \\
\hline $25 \times 18$ & & $1.60^{\mathrm{a}} \pm 0.10$ & $2.21^{\mathrm{b}} \pm 0.08$ & $15.45^{\mathrm{c}} \pm 1.49$ & $10.90^{\mathrm{b}} \pm 1.13$ & $28.06^{\mathrm{c}} \pm 4.68$ \\
\hline $30 \times 16$ & & $1.42^{\mathrm{a}} \pm 0.16$ & $2.69^{\mathrm{a}} \pm 0.11$ & $17.70^{\mathrm{b}} \pm 2.13$ & $11.66^{\mathrm{b}} \pm 1.34$ & $63.61^{\mathrm{a}} \pm 0.48$ \\
\hline $30 \times 17$ & & $1.32^{\mathrm{b}} \pm 0.07$ & $2.47^{\mathrm{a}} \pm 0.14$ & $16.33^{\mathrm{c}} \pm .54$ & $10.79^{\mathrm{b}} \pm 1.21$ & $40.76^{\mathrm{b}} \pm 6.12$ \\
\hline $30 \times 18$ & & $1.52^{\mathrm{a}} \pm 0.11$ & $2.52^{\mathrm{a}} \pm 0.17$ & $20.12^{\mathrm{a}} \pm 2.90$ & $15.52^{\mathrm{a}} \pm 0.92$ & $36.98^{\mathrm{b}} \pm 4.74$ \\
\hline $35 \times 16$ & & $1.24^{\mathrm{b}} \pm 0.15$ & $2.74^{\mathrm{a}} \pm 0.09$ & $18.65^{\mathrm{b}} \pm .86$ & $15.16^{\mathrm{a}} \pm 2.34$ & $65.99^{\mathrm{a}} \pm 12.88$ \\
\hline $35 \times 17$ & & $1.28^{\mathrm{b}} \pm 0.08$ & $2.63^{\mathrm{a}} \pm 0.13$ & $18.52^{\mathrm{b}} \pm 1.70$ & $13.65^{\mathrm{ab}} \pm 1.92$ & $51.92^{\mathrm{b}} \pm 10.84$ \\
\hline $35 \times 18$ & & $1.31^{\mathrm{b}} \pm 0.11$ & $2.54^{\mathrm{a}} \pm 0.14$ & $18.02^{\mathrm{b}} \pm 1.43$ & $14.64^{\mathrm{a}} \pm 0.83$ & $40.50^{\mathrm{b}} \pm 8.77$ \\
\hline $40 \times 16$ & & $1.12^{\mathrm{c}} \pm 0.07$ & $2.75^{\mathrm{a}} \pm 0.12$ & $21.64^{\mathrm{a}} \pm 3.24$ & $11.07^{\mathrm{b}} \pm 1.16$ & $65.74^{\mathrm{a}} \pm 12.30$ \\
\hline $40 \times 17$ & & $1.13^{\mathrm{c}} \pm 0.09$ & $2.66^{\mathrm{a}} \pm 0.16$ & $18.32^{\mathrm{b}} \pm 1.67$ & $13.96^{\mathrm{ab}} \pm 1.86$ & $56.96^{\mathrm{b}} \pm 11.42$ \\
\hline $40 \times 18$ & & $1.08^{\mathrm{c}} \pm 0.06$ & $2.39^{\mathrm{a}} \pm 0.14$ & $18.07^{\mathrm{b}} \pm 2.12$ & $13.99^{\mathrm{ab}} \pm 1.70$ & $37.95^{\mathrm{c}} \pm 9.27$ \\
\hline
\end{tabular}

Values with different superscripts letters are significantly different $(p<0.05)$.

*PER, Protein Efficiency Ratio, EER, Energy Efficiency Ratio, PD, Protein Deposition, LD, Lipid Deposition and LR, Lipid retention.

\section{CONCLUSION}

The present results showed that, the highest final body weight, weight gain, feed efficiency (\%); protein efficiency ratio (PER) and specific growth rate (SGR, \% day) values were recorded with increasing of dietary protein levels from 25 up to $35 \%$, irrespective of dietary energy levels. However, irrespective of dietary protein levels, the increasing dietary energy levels (from 16 to18 $\mathrm{MJkg}^{-1}$ diet) obtained slightly final body weight gain; weight gain, feed efficiency (\%); protein efficiency ratio (PER) and specific growth rate (SGR, \% day). Feed conversation ratio (FCR) values decreased $(P \geq 0.05)$ either with increasing dietary crude protein irrespective of dietary energy levels or dietary energy levels irrespective of dietary crude protein levels. Concomitant increase $(P<0.05)$ of body lipid and protein retained were observed with increase dietary lipid levels, may due to the protein-sparing effect of dietary lipid suggesting that Mugil cephalus may tend to the synthesis of lipid is less efficient than the synthesis of protein. These results suggested the diet contains $30 \%$ crude protein with $18 \mathrm{MJ} / \mathrm{kg}$ gross energy enhanced the growth performance, feed efficiency and had a sparing protein effect on mullet Mugile cephalus.

\section{REFERENCES}

Abdel-Tawwab,M; Eid,A.M.; Abdelghany,A.E. and El-Marakby,H.I. (2005).The Assessment of Water Quality and Primary Productivity in Earthen Fishponds Stocked with Stripped Mullet (Mugil cephalus) and Subjected to Different Feeding Regimes. Turkish Journal of Fisheries and Aquatic Sciences, 5:1-10.

AOAC (2006). Official Methods of Analysis of AOAC International, $18^{\text {th }}$ ed. Rev.1. AOAC International. (Gaithersburg, MD, USA.). 
Austreng, E.(1979). Fat and protein in diets for salmonoid fishes. VI. Digestibility and feed utilization by rainbow trout (Salmo guirdneri, Richardson) fed diets containing different levels of fat. Meld. Norg. LandbrHogsk.,58(6):1 -12.

Blaber, SJM (1976). The food and feeding ecology of Mugilidae in the St Lucia lake system. Biological Journal of the Linnean Society, 8:267-277

Boujard, T. and Medale, F.(1994). Regulation of voluntary feed intake in juvenile rainbow trout fed by hand or by self-feeders with diets containing two different protein/energy ratios. Aquac. Living Resour.,7:211-215.

Caballero, M.J.; Lo'pez-Calero, G.; Socorrob, J.; Roo, F.J.; Izquierdo, M.S. and Fe'rnandez, A.J. (1999). Combined effect of lipid level and fish meal quality on liver histology of gilthead seabream (Sparus aurata) Aquaculture,179: 277290.

Cowey, CB. and Walton, MJ. (1989). Intermediary metabolism. In Fish Nutrition, pp. 260-321 [JE Halver, editor]. San Diego, CA:Academic Press.

De silva,S.S. (1980). Biology of grey mullet: a short review. Aquaculture,19:21-36.

Duncan, D. B. 1955. Multiple Range and Multiple F- Tests. Biometrics 11:1.Eno, C. F. (1966). Chicken Manure. Fla. Agr. Exp. Sta. Circ. S-140.

EL-Sayed ,A-F., and Garling, D. L. Jr (1988). Carbohydrate-to-Lipid Ratios in Diets for Tilapia zillii Fingerlings. Aquaculture,73:157-163.

Emmans, G.C. (1994). Effective energy: a concept of energy utilization applied across species. Br. J. Nutr.,71:801-821.

Fernández,C .(2014). Variacion Estacional E Interanual de la Dieta de la Lisa, Mugil cephalus Linnaeus, 1758, Frente A Callao( $\left(12^{\circ}\right.$ S), en 2005 y 2013 seasonal and interannual variation in the diet of the striped mullet, Mugil cephalus Linnaeus, 1758, Ecología Aplicada, 13(2), 2014 Presentado:21/01/2014.

Helland, K.; Bemtsen,H.E.;Borgen,O.S. and Martens, H. (1991). Recursive algorithm for partial least squares regression. Chemnietrics and Intell. Lab. Syst., 14, 129-137.

Helland,B.G and Helland, S,G (1997). Replacement of protein by fat and carbohydrate in diets for Atlantic salmon (Salmo salar) at the end of the freshwater stage. Aquaculture Volume, 152, Issues 1-4, Pages :167-180.

Hemre, G.I.; Mommsen, T.P. and Krogdahl, A. (2002). Carbohydrates in fish nutrition:effects on growth, glucose metabolism and hepatic enzymes. Aquaculture Nutrition, 8:175-194.

Jequier, E. and Tappy, L. (1999). Regulation of body weight in humans. Physiol. Rev., 79: 451-480.Johnsen, F., Hillestad, M. and Austreng, E.(1993). High energy diets for Atlantic salmon. Effects on pollution. In: S.J. Kaushii and P. Luquet (Editors), Fish Nutrition in Practice. INRA, Paris, pp. 391-401.

Kanimozhi, S.; Krishnaveni, M.; Deivasigmani, B.; Rajasekar, T. and Priyadarshni, P. (2013). Immunology stimulation effects of Sargasso white on Mugil cephalus against Pseudomonas fluorescence. Int.J.Curr.Microbiol.App.Sci.,2(7):93-103.

Kaushik, S.J. and Me'dale, F.(1994). Energy requirements, utilization and dietary supply to Salmonids. Aquaculture, 124:81-97.

Kaushik, S. J.; Medale, F.;.Fauconneau,B. and Blanc,D. (1989).Effects of digestibl carbohydrates on protein/energy utilization and on glucose metabolism in rainbow trout (Salmo gairdneri). Aquacult., 79:63-74.

Klaoudatos, D.S.; Grove, D.J. and Klaoudatos, S.D. (2005).Voluntary food intake of gilthead sea bream, Sparus aurata. Cahiers Options Méditerranéennes, Volume, 63:p45-58. 
Krogdahl, ̊.; Hemre, G.I. and Mommsen, T.P. (2005). Carbohydrates in fish nutrition: digestion and absorption in post larval stages. Aquaculture Nutrition, 11: $103-122$.

Lin, D., (1991). Grass Carp, Ctenopharyngodon Idella. In: Handbook of Nutrient Requirements of Finfish, Wilson, R.P. (Ed.). CRC Press, Inc., Boca Raton, FL., USA., pp: 89-96.

Loftus, W.F.; J.A. Kushlan and Voorhees,S.A. (1983). Status of the mountain mullet in southern Florida. Flor. Sci. 47:257-263.

Lupatscha, I.; Kissila, G. W. and Sklan, D. (2003). Comparison of energy and protein efficiency among three fish species gilthead sea bream (Sparus aurata), European sea bass (Dicentrarchus labrax) and white grouper (Epinephelus aeneus): energy expenditure for protein and lipid deposition. Aquaculture, 225: $175-189$.

Mincklcy (1982). Trophic interrelationships among introduced fishes in the lower Colorado River, southwestern United States. California Fish and Game, 68:7889.

Montero, D.; Robaina, L.; Caballero, MJ.; Gine,' SR. and Izquierdo, MS. (2005). Growth, feed utilization and flesh quality of European sea bass (Dicentrarchus labrax) fed diets containing vegetable oils: a time course study on the effect of a re-feeding period with a 100\% fish oil diet. Aquaculture, 248:121-34.

National Research Council, NRC. (2011). Nutrient Requirements of fish and shrimp. National Academy Press, Washington, D. C., USA.

Pitcher, J.T. and Hart, J.B.P. (1982). Fisheries Ecology. Chapman \& Hall, London, $414 p$.

Romer, G.S. and McLachlan,A. (1986). Mullet grazing on surf diatom accumulations. J. Fish Biol., 28: 93-104.

Sanchez-Vazquez, F.J.; Yamamoto, T.; Akiyama, T.; Madrid, J.A. and Tabata, M. (1999). Macronutrient self-selection through demand feeders in rainbow trout. Physiol. Behav., 66: 45-51.

Sanchez-Vazquez, F.J.; Yamamoto, T.; Akiyama, T.; Madrid, J.A. and Tabata, M. (1998). Selection of macronutrients by goldfish operating self-feeder. Physiol. Behav., 65: 211-218.

Schwarz, F.J. and Kirchgessner, M. (1995). Effects of different diets and levels of feeding on retention and efficiency of utilization of energy and protein by carp (Cyprinus carpio). J. Appl. Ichthyol., 11: 363- 366.

Shiau, SY. and Peng CY. (1993). Protein-sparing effect by carbohydrates in diets for tilapia, Oreochromis niloticus $\times$ O. aureus. Aquaculture,117:327-334.

Shimeno, S. (1991). Yellowtail, Seriola quinqueradiata. Pages 18 1-1 91. In, R.P. Wi lson (editor) Handbook of nutrient requirements of finfish. CRC Press. Boca Raton, FL. USA.

SPSS Inc. (Released 2016). SPSS Statistics for Windows, Version, 16, Chicago: SPSS Inc, USA.

Tacon, A.G.J. (1997). Feeding tomorrow's fish: Keys for sustainability. In: Feeding Tomorrow's Fish, Proc. of the Workshop of the CIHEAM Network on Technology of Aquaculture in the Mediterranean, Tacon, A. and Basurco, B. (eds). Mazarrón (Spain), 24-26 June 1996. Cahiers Options Méditerranéennes, Vol. 22:11-33.

Vergara, J.M.; Robaina, L.; Izquierdo, M. and De La Higuera, M., (1996). Protein sparing effect of lipids in diets for fingerlings of gilthead sea bream. Fish. Sci. $62,624-628$. 
Wilson, R.P. (1994). Utilization of dietary carbohydrate by fish. Aquaculture, 124: 67-80.

Woods, S.C.; Seeley, R.J.; Porte, D. Jr. and Schwartz, M.W. (1998). Signals that regulate food intake and energy homeostasis. Science, 280: 1378-1383.

Wu, X.-Y.; Liu, Y.-J.; Tian, L.-X.; Mai, K.-S.; Yang, H.-J. and Liang, G.-Y. (2007). Effects of raw corn starch levels on growth, feed utilization, plasma chemical indices and enzyme activities in juvenile yellowfin seabream Sparus latus Houttuyn. Aquacult. Res., 38:1330-1338.

Yones, A.M. and Abdel -Tawab, A.M. (2005). Effect of feeding Ca-salt of fatty acids protected and non-protected fats on growth performance of mullet (Liza ramada). Egyptian J. Aquatic Biol.\&Fish, 9 (4): 117-126.

Yones,A.M.; Metwalli, A.A. and Al-Jilany, S.A. (2016). Effect of artificial diets on growth performance, body compostion and gonad maturation of mullet (Liza ramada).International Journal of Fisheries and Aquaculture Research, .2 :2849.

Yones, A.M.; Nazmi, A.M. and Metwalli,A.A. (2018).Influence of several dietary protein and lipid levels on nutritional parameters and liver functions of Solea aegyptiaca juveniles. Egyptian Journal of Aquatic Biology \& Fisheries, 22(5): 431- 445.

\section{ARABIC SUMMARY}

$$
\begin{aligned}
& \text { النسبة المثلى لمساهمة البروتين والطاقة فى علائق أسماك البورى } \\
& \text { عبد المنعم عبد الصادق مهذى يونس' - ـ أحمد كامل ابراهيم الحمادى' ـ علياء مدحت عبد الفتاح } \\
& \text { 1 إل المعهد القومى لعلوم البحار و المصايد، مصر. } \\
& \text { r- كلبة الثروة السمكية - جامعة قناة السويس، الاسماعيليه، مصر. }
\end{aligned}
$$

نم تقيم تأثير استخدام مستويات مختلفة من البروتين والطاقة على معدلات التئية النمو، الكفاءة الغذائية

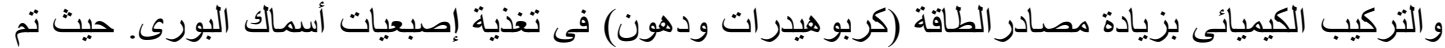

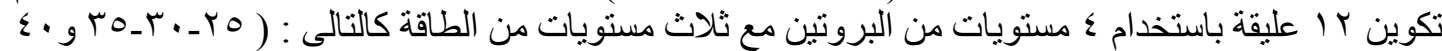

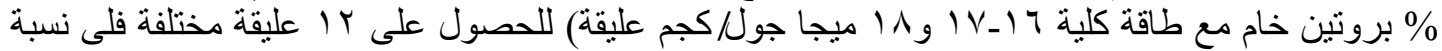

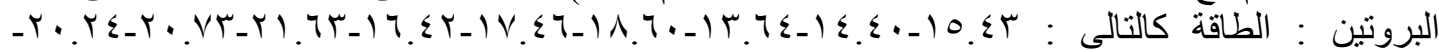

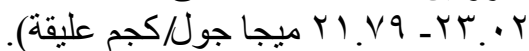

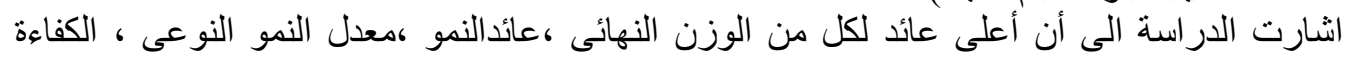

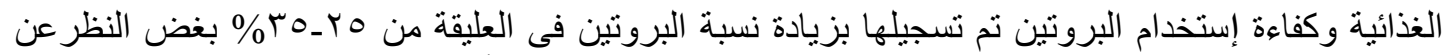

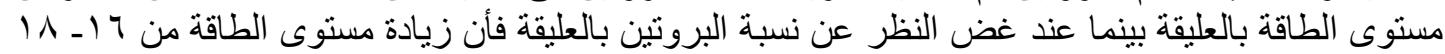

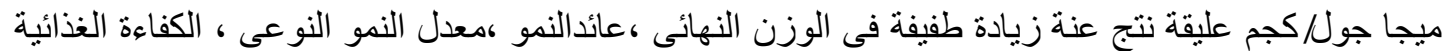

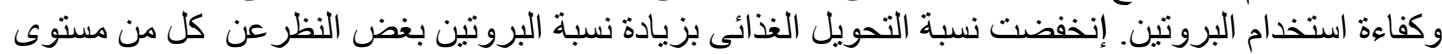

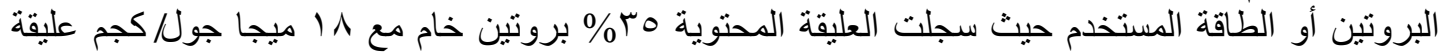

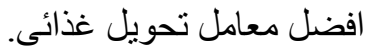

لم يحدث فرق معنوى عند مستوى( 0 •, • \% \%) في تركيب جسم الأسماك من المكونات المختلفة ماعدا

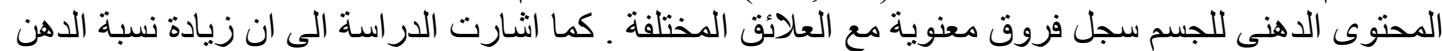

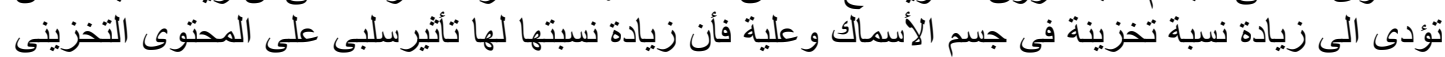

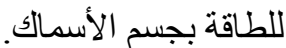

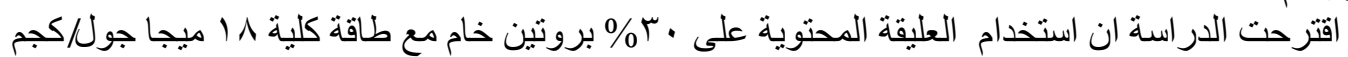

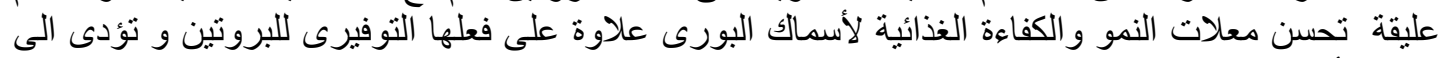
زيادة الأستفادة من كل من مصادر البروتين و الطاقة بالعليقة. 